\title{
Comparação entre os Indicadores Internos e o Método de Coleta Total na Determinação da Digestibilidade dos Nutrientes de Alimentos Volumosos, em Eqüinos ${ }^{1}$

\author{
Kleber Villela Araújo², José Augusto de Freitas Lima ${ }^{3}$, Elias Tadeu Fialho ${ }^{3}$, Eliana Sayuri Miyagi ${ }^{4}$
}

RESUMO - Foram realizados dois ensaios com o objetivo de avaliar a precisão dos indicadores internos em relação ao método de coleta total de fezes, para estimar a digestibilidade aparente dos nutrientes em dietas, em eqüinos. Foram utilizados seis cavalos adultos sem raça definida e com idade média de sete anos. No primeiro ensaio, foram comparados os valores de digestibilidade dos nutrientes do feno de capim coast-cross, utilizando-se cinza insolúvel em $\mathrm{HCl}$ (CIA), cinza insolúvel em detergente ácido (CIDA) e lignina, por intermédio do método de coleta total de fezes. No segundo ensaio, foi comparada, pelos dois métodos, a digestibilidade dos nutrientes da dieta composta de capim-elefante e feno de capim coast-cross. Utilizou-se um delineamento em blocos casualizados, no qual cada cavalo constituiu o bloco, e os métodos de determinação da digestibilidade, os tratamentos. Em ambos os ensaios, os resultados demonstraram que a CIA e CIDA foram eficientes como indicadores internos para estimar a digestibilidade aparente dos nutrientes do feno de capim coast-cross e da dieta composta de feno de capim coast-cross e capim-elefante. Nos cavalos alimentados com feno de capim coast-cross, a recuperação média de CIA e CIDA nas fezes foi de 100,12 e 99,66\%, respectivamente. Nos cavalos alimentados com feno de capim coast-cross e capim-elefante, a recuperação foi de 101,32 e 96,33\%, respectivamente. A lignina mostrou-se inadequada para estimar a digestibilidade aparente dos nutrientes das dietas testadas.

Palavras-chave: cavalos, digestibilidade, indicadores

\section{Comparison among the Internal Markers and the Total Collection Method in the Determination of the Forage Nutrients Digestibilities in Equine}

\begin{abstract}
Two assays were carried out to evaluate the precision of internal markers in relation to the total feces collection method to estimate the apparent digestibility of nutrients in diets for equines. Six adult crossbreed horses, averaging seven years old, were used. In the first assay, the values of digestibility of the nutrients of coast-cross hay using HCl-insoluble ash (AIA), acid detergent insoluble ash (ADIA) and lignin by the total feces collection method were compared. In the second assay, the digestibility of the nutrients of the combination of elephant grass and coast cross hay was compared by the two methods. A completely randomized block design was used, where each horse made up a block and the methods of digestibility determination, the treatments. In both assays, the results showed that both AIA and ADIA were efficient as internal markers to estimate the apparent digestibility of the nutrients of coast-cross hay and of the combination of elephant grass and coast-cross hay. For the horses fed coast-cross hay, the average recovery in the feces of AIA and ADIA was of 100.12 and $99.66 \%$, respectively. For the horses fed with hay and elephant grass the recovery were 101.32 and $96.33 \%$, respectively. The lignin was unsuitable to estimate the apparent digestibility of nutrients in the tested diets.
\end{abstract}

Key Words: digestibility, horses, indicators

\section{Introdução}

O conhecimento do valor nutritivo dos alimentos é indispensável na formulação de rações balanceadas e fundamental para os estudos de nutrição animal. A determinação da digestibilidade dos nutrientes de um alimento é uma das formas mais importantes para descrever o seu valor nutritivo. Ensaios de digestibilidade envolvendo a coleta total de fezes são trabalhosos e onerosos e requerem a contenção dos animais para o controle rigoroso da ingestão e excreção, o que torna a técnica, muitas vezes, impraticável. O uso dos indicadores para determinar a digestibilidade assume grande importância nos ensaios, nos quais não é possível realizar a coleta total de fezes, principalmente em condições de pastejo ou nas digestões parciais. Além disso, os indicadores apresentam outras aplicações em estudos nutricionais, como estimar a quantidade de alimento ou nutriente consumido; medir o tempo e a taxa de passagem da

\footnotetext{
${ }^{1}$ Parte da Tese de Doutorado apresentada à Universidade Federal de Lavras pelo primeiro autor.

2 Professor da FAV/UNB - Brasília - DF. E.mail: kvaraujo@unb.br

${ }^{3}$ Professor do Departamento de Zootecnia da UFLA, Lavras - MG.

4 Zootecnista.
} 
digesta total ou em qualquer parte do trato digestivo; e estimar a digestibilidade total ou parcial dos alimentos.

Para se estimar a digestibilidade dos nutrientes por meio de indicadores, pode-se optar por indicadores internos, que ocorrem naturalmente nos alimentos, ou por indicadores externos, que são adicionados à ração ou fornecidos diretamente ao animal. Na literatura consultada, são raras as pesquisas com o uso de indicadores internos para estimar a digestibilidade dos nutrientes em eqüinos. A lignina é um dos indicadores mais estudados, enquanto a cinza insolúvel em detergente ácido (CIDA) e cinza insolúvel em $\mathrm{HCl}$ (CIA) apresentam alguns resultados promissores.

Em eqüinos, SUTTON et al. (1977) não encontraram diferenças nos coeficientes de digestibilidade da energia bruta e do nitrogênio, estimados pela CIA $\mathrm{HCl} 4 \mathrm{~N}$ e pelo método de coleta total de fezes. Mais recentemente, MACHADO (1992) comparou a eficiência da CIA $\mathrm{HCl} 2 \mathrm{~N}$, cinza insolúvel em detergente ácido (CIDA), para estimar a digestibilidade dos nutrientes em eqüinos alimentados com diferentes combinações de capim-elefante e cana-de-açúcar, com o método de coleta total de fezes. O autor concluiu que tanto a CIA como CIDA mostraram-se eficientes para estimar a digestibilidade dos nutrientes em eqüinos, sendo os coeficientes de digestibilidade dos nutrientes obtidos por meio dos indicadores semelhantes àqueles determinados pelo método de coleta total de fezes.

A cinza residual da determinação da fibra em detergente ácido, conhecida como CIDA, pode ser usada como indicador interno. A CIDA tem sido empregada para estimar a digestibilidade dos nutrientes em cabras (CARVALHO, 1989), em bovinos (OLIVEIRA, 1990) e eqüinos (MACHADO, 1992), com resultados satisfatórios. Sherrod et al. (1978), citados por CARVALHO (1989), trabalhando com nível de CIDA próximo ou maior que $3 \%$ na ração, não encontraram diferenças na determinação da digestibilidade da MS, MO, parede celular e do conteúdo celular, quando a CIDA foi comparada ao método de coleta total de fezes. Porém, em rações nas quais o nível de CIDA foi menor que $3 \%$, os resultados de digestibilidade foram subestimados, devido à dificuldade de recuperação da CIDA nas fezes.

A lignina é utilizada como indicador interno, mas, devido à indefinição de sua composição química e conseqüente variação dos resultados de análises, tem apresentado estimativas variáveis dos coeficientes de digestibilidade (FAHEY e JUNG, 1983). Esses autores, revisando o uso da lignina como indicador, verificaram que a lignina foi digerida em rações contendo $100 \%$ de forragem e até $90 \%$ de concentrado, podendo, por conseguinte, ser usada como indicador somente quando apresentar evidências de sua alta recuperação fecal.

Existem vários fatores que afetam a recuperação da lignina. MUNTIFERING (1982) citou as prováveis razões da ineficiência da recuperação da lignina: diferenciação dos monômeros fenólicos da lignina original (digestão verdadeira); digestão aparente obtida pela formação de complexos solúveis ligninacarboidratos; destruição parcial da lignina fecal pelos reagentes usados nos métodos analíticos; e diferenças físicas e/ou químicas entre os alimentos e as fezes na natureza do material definido como lignina.

Em eqüinos, FONNESBECK (1968) encontrou variações na digestibilidade da lignina em leguminosas, de $-15,60$ a 4,80\%, e em gramíneas, de 0 a $16,40 \%$. MAURÍCIO (1993) comparou os valores de digestibilidade de uma ração composta de feno de capim coast-cross e concentrado, estimados por meio da lignina e do óxido crômico, com o método de coleta total de fezes. Os resultados mostraram que a lignina e óxido crômico subestimaram os coeficientes de digestibilidade aparente da MS, PB, EB, FDN e FDA, devido às suas baixas recuperações. Resultados semelhantes foram obtidos por MACHADO (1992) com potros alimentados com diferentes combinações de cana-de-açúcar e capim-elefante, em que a lignina apresentou recuperação fecal média de $58,33 \%$, permitindo concluir que foi ineficiente para estimar a digestibilidade dos nutrientes em eqüinos.

Objetivou-se nesta pesquisa comparar os coeficientes de digestibilidade dos nutrientes do feno de capim coast-cross e da dieta composta de feno de capim coast-cross e capim-elefante, obtidos pelo método de coleta total de fezes, com os valores estimados pela cinza insolúvel em $\mathrm{HCl}$ a $2 \mathrm{~N}$, cinza insolúvel em detergente ácido e lignina.

\section{Material e Métodos}

Foram conduzidos dois ensaios de digestão, nos quais se utilizaram seis cavalos adultos, castrados, sem raça definida, com idade e peso médios de sete anos e 334 e $355 \mathrm{~kg}$ para os ensaios 1 e 2, respectivamente.

Os tratamentos foram constituídos de dois métodos para determinar a digestibilidade aparente dos nutrientes: o método da coleta total de fezes e o método indireto, utilizando os indicadores internos. No método indireto, utilizaram-se os indicadores 
lignina, cinza insolúvel em ácido clorídrico a $2 \mathrm{~N}$ (CIA) e cinza insolúvel em detergente ácido (CIDA). No primeiro ensaio, foram comparados os valores de digestibilidade dos nutrientes do feno de capim coastcross, pelos dois métodos, e no segundo ensaio, os coeficientes de digestibilidade da dieta composta de $60 \%$ feno de capim coast-cross e $40 \%$ capimelefante com base na matéria seca, também por intermédio dos dois métodos, totalizando quatro tratamentos em cada ensaio.

Cada ensaio de digestão foi conduzido durante um período de 20 dias, divididos em uma fase préexperimental de 15 dias e uma fase experimental de cinco dias. Durante a fase pré-experimental, adaptaram-se os cavalos às gaiolas metabólicas e determinou-se o consumo voluntário dos animais. Nos cinco dias finais, procedeu-se às coletas de fezes. A alimentação foi fixada em $80 \%$ do consumo voluntário determinado durante o período de adaptação, com o objetivo de evitar sobras.

Foram realizadas quatro refeições diárias, às 8 , 13, 17 e $22 \mathrm{~h}$, e a água foi completada também nos mesmos horários, para que sempre houvesse água disponível. O feno de capim coast-cross fornecido aos animais foi moído em moinho de martelo com peneira de $1,1 \mathrm{~cm}$ de diâmetro e o capim-elefante foi picado antes de ser fornecido aos cavalos.

As fezes foram coletadas três vezes ao dia, às 7 , 16 e 21 h. Após a coleta, as fezes foram pesadas, homogeneizadas, amostradas em $10 \%$ e armazenadas à temperatura de $-15^{\circ} \mathrm{C}$, para posterior análise. Os alimentos foram amostrados em 5\% do fornecido, quatro vezes ao dia no momento do fornecimento, e armazenados para posterior análise. As amostras diárias de fezes e volumosos formaram uma amostra composta ao final dos cinco dias de coleta.
Nas amostras de fezes, feno de capim coast-cross e capim-elefante, foram realizadas análises de matéria seca (MS), proteína bruta (PB), energia bruta (EB), fibra em detergente neutro (FDN), fibra em detergente ácido (FDA), lignina e cinza insolúvel em detergente ácido (CIDA), segundo SILVA (1981), e cinza insolúvel em ácido clorídrico a 2N (CIA), segundo a metodologia de VAN KEULEN e YOUNG (1977). As composições químicas do feno de capim coast-cross $\mathrm{e}$ do capim-elefante encontram-se na Tabela 1.

$\mathrm{Na}$ análise dos coeficientes de digestibilidade dos nutrientes do feno de capim coast-cross ou da dieta composta de feno de capim coast-cross e capimelefante, foi utilizado um delineamento em blocos casualizados, com quatro tratamentos (coleta total de fezes e indicadores internos) e seis repetições (cavalo). O modelo utilizado foi o seguinte:

em que

$$
\left.Y i j=\mu+B_{i}+M_{j}+E_{(i j}\right)
$$

Yij = coeficientes de digestibilidade aparente dos nutrientes das dietas referentes ao cavalo i e ao método j;

$\mu \quad=$ constante associada a todas as observações;

$\mathrm{B}_{\mathrm{i}} \quad=$ efeito do cavalo $\mathrm{i}$, sendo $\mathrm{i}=1,2,3,4,5,6$;

$\mathrm{M}_{\mathrm{j}}=$ efeito do método $\mathrm{j}$, sendo $\mathrm{j}=1,2,3$, 4; e

$\mathrm{E}(\mathrm{ij})=$ erro aleatório associado a cada observação que, por hipótese, tem distribuição normal, média zero e variância $\sigma^{2}$.

Os resultados foram analisados pelo programa computacional SAEG - Sistema de Análise Estatística e Genética (UNIVERSIDADE FEDERAL DE VIÇOSA - UFV, 1997). Foi utilizado o teste Student Newman Keuls para comparar as médias dos coeficientes de digestibilidade aparente dos nutrientes das dietas.

Tabela 1 - Composição química do feno de capim coast-cross e do capim-elefante fornecidos aos cavalos Table 1 - Chemical composition of the coast-cross hay and elephant grass fed to horses

\begin{tabular}{|c|c|c|c|c|c|c|c|c|c|c|}
\hline \multirow[t]{2}{*}{$\begin{array}{l}\text { Alimento } \\
\text { Feed }\end{array}$} & \multicolumn{10}{|c|}{$\begin{array}{l}\text { Composição química na \% matéria seca } \\
\text { Chemical composition in } \% \text { dry matter }\end{array}$} \\
\hline & $\begin{array}{l}\text { MS } \\
(\%) \\
D M\end{array}$ & $\begin{array}{l}\mathrm{MO} \\
(\%) \\
O M\end{array}$ & $\begin{array}{c}\mathrm{PB} \\
(\%) \\
C P\end{array}$ & $\begin{array}{c}\mathrm{EB} \\
\mathrm{kcal} / \mathrm{kg} \\
G E\end{array}$ & $\begin{array}{c}\mathrm{FDN} \\
(\%)\end{array}$ & $\begin{array}{c}\text { FDA } \\
(\%) \\
A D F\end{array}$ & $\begin{array}{c}\mathrm{HEM} \\
(\%) \\
H F M\end{array}$ & $\begin{array}{l}\mathrm{LIG} \\
(\%)\end{array}$ & $\begin{array}{l}\text { CIA } \\
(\%)\end{array}$ & $\begin{array}{c}\text { CIDA } \\
(\%)\end{array}$ \\
\hline $\begin{array}{l}\text { Feno de capim coast-cross } \\
\text { Coast-cross hay }\end{array}$ & 88,47 & 96,05 & 6,41 & 4448 & 84,64 & 40,15 & 44,49 & 9,10 & 1,07 & 1,00 \\
\hline $\begin{array}{l}\text { Capim-elefante } \\
\text { Elephant grass }\end{array}$ & 40,26 & 96,65 & 8,65 & 4095 & 80,79 & 53,66 & 27,13 & 11,06 & 1,74 & 1,38 \\
\hline
\end{tabular}

\footnotetext{
1 Pré-seco por 1 dia no campo.
}

1 Pre-dry for 1 day in the field. 


\section{Resultados e Discussão}

O consumo médio de matéria seca diário por $100 \mathrm{~kg}$ de peso corporal, consumo médio diário de proteína bruta por $100 \mathrm{~kg}$ de peso corporal e consumo médio de energia digestível diário do feno de capim coast-cross foram de 2,23 kg, 134,9 g, $14.110 \mathrm{kcal}$, respectivamente. Estes valores, mesmo que limitados, foram adequados para atender às exigências diárias de mantença de MS, PB e ED dos cavalos, segundo o NATIONAL RESEARCH COUNCIL NRC (1989). Apenas um cavalo apresentou consumo de PB abaixo da exigência. O nível de consumo parece não afetar a digestibilidade dos nutrientes em eqüinos. Segundo TODD et al. (1995), em cavalos adultos alimentados com feno de alfafa na forma de cubos ao nível de mantença e 1,4 vez acima da mantença, a digestibilidade da MS, EB, PB e o tempo de trânsito da digesta não foram afetados. Nesta pesquisa, foram fornecidas quatro refeições diárias, com o objetivo de evitar perdas, devido à pequena capacidade do comedouro das gaiolas metabólicas. De acordo com Butler e Hintz (1973), citados por CUNHA (1991), o fornecimento de 1, 2 e 6 alimentações diárias a pôneis na forma peletizada não afetou os coeficientes de digestibilidade da MS, PB, FDN e FDA.

O consumo médio de matéria seca diário por $100 \mathrm{~kg}$ de peso corporal, consumo médio diário de
RAÚJO et al.

proteína bruta por $100 \mathrm{~kg}$ de peso corporal e consumo médio de energia digestível diário da dieta composta do feno de capim coast-cross e capim-elefante foram de $1,87 \mathrm{~kg}, 133,6 \mathrm{~g}$ e $10.139 \mathrm{kcal}$, respectivamente. As exigências de mantença de MS e PB dos cavalos, exceto de um cavalo, foram atendidas pela dieta composta de $60 \%$ de feno de capim coast-cross e $40 \%$ de capim-elefante, mesmo com consumo limitado em $80 \%$ do consumo voluntário. Os consumos de ED dos cavalos não foram adequados para atender a exigência de mantença dos animais, ficando, em média, $18 \%$ abaixo do valor ideal (NRC, 1989). A ingestão diária média de água por kg de matéria do feno de capim coast-cross e da dieta composta de feno de coast-cross e capim-elefante foi de 3,02 e $3,16 \mathrm{~kg}$, respectivamente, mostrando estar dentro dos limites de 2 a 4 litros por kg de MS, citados pelo NRC (1989) e por CUNHA (1991).

As porcentagens de recuperação dos indicadores estão apresentadas na Tabela 2. Os resultados de recuperação fecal de CIA e CIDA estão bastante próximos de $100 \%$, enquanto a recuperação da lignina nas fezes foi abaixo de $90 \%$. Para que a CIA possa ser usada com precisão para estimar a digestibilidade dos nutrientes em ruminantes, THONNEY et al. (1984) recomendam que a ração ou o alimento contenha teor de $0,75 \%$ de CIA ou mais na matéria seca. Já para a CIDA, a porcentagem adequada deverá ser próximo

Tabela 2 - Composição na dieta e porcentagem média de recuperação fecal da lignina, cinza insolúvel em $\mathrm{HCl}(\mathrm{CIA})$ e cinza insolúvel em detergente ácido (CIDA) para os cavalos alimentados com feno de capim coast-cross e feno de capim coast-cross mais capimelefante, com seus respectivos erros-padrão

Table 2 - Composition in the diet and average percentage of the fecal recovery of the lignin, $\mathrm{HCl}$ - insoluble ash (AIA) and acid detergent insoluble ash (ADIA) to the horses fed coast-cross hay and coast-cross hay plus elephant grass, with respective standard errors

\begin{tabular}{|c|c|c|}
\hline $\begin{array}{l}\text { Indicador } \\
\text { Indicator }\end{array}$ & $\begin{array}{l}\text { Composição na dieta }(\%) \\
\text { Composition in the diet }\end{array}$ & $\begin{array}{c}\text { Porcentagem média de recuperação }(\%) \\
\text { Average percentage of the recovery }\end{array}$ \\
\hline & & $\begin{array}{l}\text { Feno de capim coast-cross } \\
\text { Coast-cross hay }\end{array}$ \\
\hline Lignina & 9,10 & $81,36 \pm 2,03$ \\
\hline \multicolumn{3}{|l|}{ Lignin } \\
\hline CIA & 1,07 & $100,12 \pm 1,51$ \\
\hline \multicolumn{3}{|l|}{$A I A$} \\
\hline CIDA & 1,00 & $99,66 \pm 1,24$ \\
\hline \multicolumn{3}{|l|}{$A D I A$} \\
\hline & & $\begin{array}{c}\text { Feno de capim coast-cross + capim-elefante } \\
\text { Coast-cross hay + elephant grass }\end{array}$ \\
\hline Lignina & 10,27 & $89,46 \pm 1,41$ \\
\hline \multicolumn{3}{|l|}{ Lignin } \\
\hline CIA & 1,27 & $101,32 \pm 1,20$ \\
\hline \multicolumn{3}{|l|}{$A I A$} \\
\hline CIDA & 1,11 & $96,33 \pm 2,28$ \\
\hline$A D I A$ & & \\
\hline
\end{tabular}


ou maior que 3\% na ração, para evitar dificuldades na recuperação (Sherrod et al., 1978, citados por CARVALHO, 1989). Nesta pesquisa, os valores de CIA e CIDA presentes no feno de capim coast-cross foram de 1,07 e $1,0 \%$ da MS, respectivamente. Isto mostra que, para a CIA, o valor analisado foi superior ao preconizado e para a CIDA, abaixo do ideal; todavia esta pode ser considerada bom indicador de digestibilidade.

A baixa recuperação da lignina observada é fator limitante para o seu uso como indicador. A recuperação incompleta da lignina foi verificada em ruminantes por vários autores (KOTB e LUCKEY, 1972; FAHEY e JUNG, 1983; CARVALHO, 1989; e OLIVEIRA, 1990). Em eqüinos, FONNESBECK (1968) e MAURÍCIO (1993) obtiveram resultados insatisfatórios no uso da lignina, como indicador, para estimar a digestibilidade aparente dos nutrientes. MACHADO (1992) verificou, em potros alimentados com diferentes combinações de cana-de-açúcar e capim-elefante, recuperação média da lignina de 58,33\%.

Segundo MUNTIFERING (1982), existem vários fatores que afetam a recuperação da lignina, entre eles a digestão aparente e a falta de estrutura química definida são as mais citadas na literatura. VAN SOEST (1994) verificou digestibilidade aparente de 20 a $40 \%$ em gramíneas imaturas e forragens com baixo conteúdo de lignina. De acordo com esse autor, a lignina poderá ser usada como indicador em rações com alto conteúdo de lignina, quando tiver acima de
$5 \%$ na matéria seca. Nesta pesquisa, apesar de o teor de lignina nas dietas ter sido maior que 5\% na MS, a recuperação da lignina foi baixa, $81,36 \%$. A digestibilidade aparente da lignina tem sido atribuída à baixa precisão dos métodos usados para quantificála. Esses métodos são considerados empíricos e diferem entre si para estimar o conteúdo de lignina nos alimentos (FAHEY e JUNG, 1983). Na análise da lignina em ácido sulfúrico a $72 \%$, a cutina e os produtos de Maillard são mensurados como lignina, sendo que parte da lignina verdadeira poderá ser destruída. Na análise de lignina em permanganato, poderão estar incluídos certos taninos, pigmentos ou proteínas que resistem à solubilização em detergente ácido, mas são oxidados pelo permanganato (FAHEY e JUNG, 1983). Segundo MUNTIFERING (1982), a análise por espectrofotometria de compostos fenólicos, como a lignina solúvel em acetil bromido, pode apresentar sensibilidade necessária para detectar componentes solúveis da lignina, que normalmente não são mensurados ou podem ser destruídos na análise, quando se utilizam os métodos gravimétricos, como nesta pesquisa.

Os resultados dos coeficientes de digestibilidade aparente da matéria seca, matéria orgânica, proteína bruta, energia bruta, fibra em detergente neutro, fibra em detergente ácido e hemicelulose do feno de capim coastcross e da dieta composta de feno de capim coast-cross ecapim-elefante, usandoos dois métodos de digestibilidade, encontram-se nas Tabelas 3 e 4, respectivamente.

Tabela 3 - Coeficientes de digestibilidade aparente da matéria seca (CDAMS), matéria orgânica (CDAMO), proteína bruta (CDAPB), energia bruta (CDAEB), fibra em detergente neutro (CDAFDN), fibra em detergente ácido (CDAFDA) e hemicelulose (CDAHE) do feno de capim coast-cross usando indicadores internos e o método de coleta total de fezes

Table 3 - Coefficients of apparent digestibility of the dry matter (CADDM), organic matter (CADOM), crude protein $(C A D C P)$, gross energy (CADGE), neutral detergent fiber (CADNDF), acid detergent fiber (CADADF) and hemicellulose (CADHE) of the coast-cross hay using internal markers and the total collection method

\begin{tabular}{|c|c|c|c|c|c|c|c|}
\hline \multirow[t]{2}{*}{$\begin{array}{l}\text { Tratamento } \\
\text { Treatment }\end{array}$} & \multicolumn{7}{|c|}{$\begin{array}{c}\text { Coeficiente de digestibilidade aparente }(\%) \\
\text { Coefficients of apparent digestibility }\end{array}$} \\
\hline & $\begin{array}{l}\text { CDAMS } \\
C A D D M\end{array}$ & $\begin{array}{l}\text { CDAMO } \\
\text { CADOM }\end{array}$ & $\begin{array}{l}\text { CDAPB } \\
C A D C P\end{array}$ & $\begin{array}{l}\text { CDAEB } \\
C A D G E\end{array}$ & $\begin{array}{l}\text { CDAFDN } \\
C A D N D F\end{array}$ & $\begin{array}{l}\text { CDAFDA } \\
C A D A D F\end{array}$ & $\begin{array}{l}\text { CDAHE } \\
\text { CADHE }\end{array}$ \\
\hline $\begin{array}{l}\text { Lignina } \\
\text { Lignin }\end{array}$ & $29,65^{b}$ & $30,14^{b}$ & $26,10^{b}$ & $28,81^{b}$ & $32,36^{\mathrm{b}}$ & $18,88^{\mathrm{b}}$ & $44,50^{\mathrm{b}}$ \\
\hline $\begin{array}{l}\text { CIA } \\
\text { AIA }\end{array}$ & $43,05^{\mathrm{a}}$ & $43,45^{\mathrm{a}}$ & $40,14^{\mathrm{a}}$ & $42,36^{\mathrm{a}}$ & $45,27^{\mathrm{a}}$ & $34,30^{\mathrm{a}}$ & $55,16^{\mathrm{a}}$ \\
\hline $\begin{array}{l}\text { CIDA } \\
A D I A\end{array}$ & $42,74^{\mathrm{a}}$ & $43,14^{\mathrm{a}}$ & $39,85^{\mathrm{a}}$ & $42,05^{\mathrm{a}}$ & $44,94^{\mathrm{a}}$ & $33,95^{\mathrm{a}}$ & $54,84^{\mathrm{a}}$ \\
\hline $\begin{array}{l}\text { Coleta total } \\
\text { Total collection }\end{array}$ & $43,01^{\mathrm{a}}$ & $43,41^{\mathrm{a}}$ & $40,13^{\mathrm{a}}$ & $42,33^{\mathrm{a}}$ & $45,22^{\mathrm{a}}$ & $34,25^{\mathrm{a}}$ & $55,09^{a}$ \\
\hline$\overline{\mathrm{CV}(\%)}$ & 7,17 & 7,03 & 8,10 & 7,42 & 6,58 & 10,39 & 4,61 \\
\hline
\end{tabular}

Médias seguidas de mesma letra na coluna são diferentes $(P<0,05)$ pelo teste SNK.

Means followed by different letters within a column are different $(P<.05)$ by SNK test. 
Tabela 4 - Coeficientes de digestibilidade aparente da matéria seca (CDAMS), matéria orgânica (CDAMO), proteína bruta (CDAPB), energia bruta (CDAEB), fibra em detergente neutro (CDAFDN), fibra em detergente ácido (CDAFDA) e hemicelulose (CDAHE) do feno de capim coast-cross e capim-elefante, usando indicadores internos e o método de coleta total de fezes

Table 4 - Coefficients of apparent digestibility of the dry matter (CADDM), organic matter (CADOM), crude protein (CADCP), gross energy (CADGE), neutral detergent fiber (CADNDF), acid detergent fiber (CADADF) and hemicellulose (CADHE) of the coast-cross hay and elephant grass, using internal markers and the total collection method

\begin{tabular}{|c|c|c|c|c|c|c|c|}
\hline \multirow[t]{2}{*}{$\begin{array}{l}\text { Tratamento } \\
\text { Treatment }\end{array}$} & \multicolumn{7}{|c|}{$\begin{array}{c}\text { Coeficiente de digestibilidade aparente (\%) } \\
\text { Coefficients of apparent digestibility }\end{array}$} \\
\hline & $\begin{array}{l}\text { CDAMS } \\
C A D D M\end{array}$ & $\begin{array}{l}\text { CDAMO } \\
\text { CADOM }\end{array}$ & $\begin{array}{l}\text { CDAPB } \\
C A D C P\end{array}$ & $\begin{array}{l}\text { CDAEB } \\
C A D G E\end{array}$ & $\begin{array}{l}\text { CDAFDN } \\
C A D N D F\end{array}$ & $\begin{array}{l}\text { CDAFDA } \\
C A D A D F\end{array}$ & $\begin{array}{l}\text { CDAHE } \\
C A D H E\end{array}$ \\
\hline $\begin{array}{l}\text { Lignina } \\
\text { Lignin }\end{array}$ & $30,53^{c}$ & $30,58^{\mathrm{c}}$ & $51,58^{\mathrm{c}}$ & $28,78^{\mathrm{c}}$ & $31,82^{c}$ & $14,35^{\mathrm{c}}$ & $52,03^{c}$ \\
\hline $\begin{array}{l}\text { CIA } \\
A I A\end{array}$ & $38,72^{\mathrm{a}}$ & $38,77^{\mathrm{a}}$ & $57,28^{\mathrm{a}}$ & $37,15^{\mathrm{a}}$ & $39,85^{\mathrm{a}}$ & $24,44^{\mathrm{a}}$ & $57,67^{\mathrm{a}}$ \\
\hline $\begin{array}{l}\text { CIDA } \\
A D I A\end{array}$ & $35,43^{b}$ & $35,48^{\mathrm{b}}$ & $54,99^{\mathrm{b}}$ & $33,76^{\mathrm{b}}$ & $36,61^{b}$ & $20,39^{b}$ & $55,37^{\mathrm{b}}$ \\
\hline $\begin{array}{l}\text { Coleta total } \\
\text { Total collection }\end{array}$ & $37,93^{\mathrm{ab}}$ & $37,98^{\mathrm{ab}}$ & $57,10^{\mathrm{a}}$ & $36,35^{\mathrm{ab}}$ & $39,05^{\mathrm{ab}}$ & $23,47^{\mathrm{ab}}$ & $57,08^{a b}$ \\
\hline$\overline{\mathrm{CV}(\%)}$ & 5,92 & 5,90 & 2,75 & 6,28 & 5,57 & 12,55 & 2,57 \\
\hline
\end{tabular}

Médias seguidas de mesma letra na coluna são diferentes pelo teste SNK $(P<0,05)$.

Means followed by different letters within a column are different $(P<.05)$ by SNK test.

Foram verificadas diferenças $(\mathrm{P}<0,05)$ entre os métodos usados para estimar a digestibilidade dos nutrientes do feno de capim coast-cross e da dieta composta de feno de capim coast-cross e capimelefante. Os coeficientes de digestibilidade dos nutrientes das duas dietas determinados por meio da lignina foram subestimados em relação aos demais indicadores e ao método de coleta total de fezes. A CIA e CIDA proporcionaram valores de digestibilidade dos nutrientes do feno de capim coastcross semelhantes ao método de coleta total de fezes, enquanto, na dieta contendo feno de capim coast-cross e capim-elefante, a PB foi subestimada pela CIDA.

As altas recuperações da CIA e CIDA para os cavalos alimentados com os dois tipos de dietas proporcionaram estimativas precisas de digestibilidade dos nutrientes em relação ao método de coleta total de fezes. MACHADO (1992) também constatou alta porcentagem de recuperação da CIA $(101,06 \%)$ e CIDA $(98,21 \%)$ nas fezes de cavalos alimentados com uma dieta contendo diferentes proporções de capim-elefante e cana-de-açúcar. O uso satisfatório da CIA, como indicador interno, para estimar a digestibilidade dos nutrientes em dieta para eqüinos foi verificado por SUTTON et al. (1977).

\section{Conclusões}

A CIA e CIDA foram eficientes como indicadores internos para estimar a digestibilidade aparente do feno de capim coast-cross e da dieta composta de feno de capim coast-cross e capim-elefante.

A lignina mostrou-se inadequada como indicador interno para estimar a digestibilidade aparente do feno de capim coast-cross e da dieta composta de feno de capim coast-cross e capim-elefante.

\section{Referências Bibliográficas}

CARVALHO, F.F.R. Efeitos de diferentes níveis de proteína bruta para cabras em lactação e uso de indicadores internos para estimar a digestibilidade dos nutrientes. Viçosa, MG: UFV, 1989, 72p. Dissertação (Mestrado em Zootecnia) Universidade Federal de Viçosa, 1989.

CUNHA, T.J. 1991. Horse feeding and nutrition. Gainesville: Academic Press, 2ed. 445p.

FAHEY, G.C., JUNG, H.G. 1983. Lignin as a marker in digestion studies: a review. J. Anim. Sci., 57(1):220-225.

FONNESBECK, P.V. 1968. Digestion of soluble and fibrous carbohydrate of forrage by horse J. Anim. Sci., 7(6):1336-1344.

KOTB, A R., LUCKEY, T.D. 1972. Markers in nutrition. Nutr. Abst. \& Rev., 42(3):814-845.

MACHADO, H.M. Efeitos de diferentes combinações de capimelefante (Pennisetum purpureum, Schum): cana-de-açúcar 
(Saccharum officinarum, L.) sobre a digestibilidade em eqüinos, utilizando diferentes metodologias de determinação. Viçosa, MG: UFV, 1992. 71p. Dissertação (Mestrado em Zootecnia) - Universidade Federal de Viçosa, 1992.

MAURÍCIO, R.M. Determinação da digestibilidade aparente em eqüideos através do óxido crômico, da lignina e da coleta total das fezes. Belo Horizonte, MG: UFMG, 1993. 62p. Dissertação (Mestrado em Zootecnia) - Universidade Federal de Minas Gerais, 1993.

MUNTIFERING, R.B. 1982. Evaluation of various lignin assays for determining ruminal digestion of roughages by lambs. $J$. Anim. Sci., 55(2):432-438.

NATIONAL RESEARCH COUNCIL - NRC. 1989. Nutrient requeriments of horses. 5.ed.rev., Washington. D.C. 100p.

OLIVEIRA, R.F.M. Estimativa da digestibilidade através de indicadores e coleta total de fezes, consumo alimentar e biometria do trato gastrintestinal, em bovinos de 3 grupos genéticos. Viçosa, MG: UFV, 1990. 77p. Dissertação (Mestrado em Zootecnia) - Universidade Federal de Viçosa, 1990.

SILVA, D.J. 1981. Análise de alimentos (Métodos químicos e biológicos). Viçosa: UFV. 166p.

SUTTON, E.I., BOWLAND, J.P., McCARTHY, J.F. 1977. Sudies with horses comparing $4 \mathrm{~N}-\mathrm{HCl}$ insoluble ash as index material with total fecal collection in the determination of apparent digestibilities. Canad. J. Anim. Sci., 57:543-549.

THONNEY, M.L., PALHOF, B.A, De CARLO, M.R. et al. 1984. Sources od variation of dry matter digestibility measured by the acid insoluble ash marker. J. Dairy Sci., 68(3):661-668.
TODD, K.L., SAUER, W.C., CHRISTOPHERSON, R.J. et al. 1995. The effect of level of feed intake on nutrient and energy digestibility and rate of feed passage in horses. J. Anim. Phys. Anim. Nut., 73:140-148

UNIVERSIDADE FEDERAL DE VIÇOSA- UFV. 1997. Sistema para análises estatísticas e genética - SAEG, Viçosa: UFV, Manual do usuário, 150p. (versão7.0).

VANDER NOOT, G.W., FONNESBECK, P.V., LYDMAN, R.K. 1965. Equine metabolism stall and collection harness. J. Anim. Sci., 24(3):691-698.

VAN KEULEN, F., YOUNG, B.A 1977. Evaluation of acidinsoluble ash as a natural marker in ruminant digestibility studies. J. Anim. Sci., 44(2):282-287.

VAN SOEST, P.J. 1994. Nutritional ecology of the ruminant. Ithaca: Cornell University Press. 476p.

Recebido em: 25/02/99

Aceito em: 29/10/99 